\title{
Overexpression of the recombinant xyloglucanase sp-Xeg from Penicillium canescens accelerates growth and rooting of transgenic aspen plants
}

\author{
Vidyagina Elena ${ }^{1,2^{*}}$, Kovalitskaya Yulia ${ }^{1,2}$, Loginov Dmitry ${ }^{3}$, Koroleva Olga $^{3}$, \\ Shestibratov Konstantin ${ }^{1,2^{*}}$ \\ ${ }^{1}$ Branch of Shemyakin, Ovchinnikov Institute of Bioorganic Chemistry, Russian Academy of Sciences, Pushchino, Russia; \\ *Corresponding Author: vidjagina@mail.ru, schestibratov@,fibkh.serpukhov.su \\ ${ }^{2}$ Pushchino State Institute of Natural Science, Pushchino, Russia \\ ${ }^{3}$ Bach Institute of Biochemistry, Russian Academy of Sciences, Moscow, Russia
}

Received 24 April 2013; revised 24 May 2013; accepted 4 June 2013

Copyright (C) 2013 Vidyagina Elena et al. This is an open access article distributed under the Creative Commons Attribution License, which permits unrestricted use, distribution, and reproduction in any medium, provided the original work is properly cited.

\begin{abstract}
Analysis of the properties of transgenic aspen clones with recombinant gene xyloglucanase $s p-X e g$ from fungi Penicillium canescens showed the presence of complex modifications both in the wood and the phenotype of plants. Biometric analysis revealed an increase in the height of transgenic plants as compared to control plants. Increasing in the height of the shoot of $24.8 \%$, $25 \%$ and $26 \%$ was observed for lines PtXIVXeg1a, PtXVXeg1a, PtXVXeg1b, respectively. Also there was an increase in the number of internodes in some transgenic clones. For the first time we showed the change in plants rhizogenesis with the recombinant gene xyloglucanase. In 10 of the 25 lines the rooting efficiency in vitro exceeded the control value. The maximum value of the rhizogenesis was fixed for line PtXVXeg1a (2.5 times higher than the control value). The mass of the root system for 6 of the 25 clones in the greenhouse was higher by $20 \%$ than the control value. The pentosan content decrease was also detected in all wood samples of transgenic plants. The obtained data of xyloglucanase activity and pentosan content generally correlated with phenotypic modifications.
\end{abstract}

Keywords: Populus Tremula; Activity of Xyloglucanase; Pentosans; Efficiency of Rooting

\section{INTRODUCTION}

The growth of plant cells is accompanied by elongation of the cell wall under the action of intracellular pressure. It is known that xyloglucan is a polysaccharide of plant cell wall hemicellulose which compounds adjacent cellulose microfibrils, providing the formation of a solid structure [1]. Separation of cell wall microfibrils in the growing plant cells is provided by enzymes that decompose xyloglucans and weaken the links between the microfibrilles [2]. Xyloglucanase is one of these enzymes from the group of carbohydrases which hydrolyzes xyloglucans and destroys the transverse links of cellulose microfibrils, and provides in this way the stretching of the cell wall. It is supposed that xyloglucanases overexpression can effect plant growth and development.

At present the overexpression of carbohydrases that decompose xyloglucan chain is considered as a promising way to modify the phenotype and increase the productivity of trees. Park et al. [3] demonstrate that white poplar (Populus alba) transformed by gene of xyloglucanases AaXEG2 from fungus Aspergillus aculeatus have an increase in the length of the stems and the change in the leaves color in comparison with the control. Transgenic plants of aspen (Populus tremula) with cell gene of endoglucanase from Arabidopsis thaliana showed significant phenotypic changes, such as an increase in the height, leaf size, diameter of trunk and a higher content of cellulose and hemicelluloses compare to non-transgenic control [4]. It was also observed that in leaves morphology, increase in the length of the petiole and midrib length reduction in plants of aspen with recombinant gene of xyloglucanases $s p$-Xeg [5]. The genetic modification of Paraserianthes falcataria was made by gene of xyloglucanase $p A a X E G$ [6]. As a result the transgenic plants had a greater length of internodes than plants of the control line. Similar results were also shown in xyloglucanase overexpression in poplar plants [3]. 
Decomposition of xyloglucans in cell wall may affect the whole range of biochemical reactions; apart from the increase in the size of organs, it may have effects on other features of the plant. This is confirmed by the studies conducted on Arabidopsis thaliana where a change of the hydrolysis of xyloglucan alters the length of petiole [7], length of the thread anther main rib and also changes the shape of trichomes [8].

It is known that overexpression of recombinant genes is often accompanied by pleiotropic effects [3-5]. The influence of a single gene can lead to a change not only in one feature but on all phenotype and ontogeny as a whole [9-11]. In this regard, for the correct evaluation of the properties of new transgenic plants it is necessary to carry out a detailed analysis across a range of parameters (growth rate, leaf morphology, rhizogenesis efficiency, root biomass, the composition of wood, etc.).

The aim of our work is to study the different phenotypic and biochemical properties of transgenic aspen with recombinant gene of xyloglucanase $s p$-Xeg from the fungus Penicillium canescens.

\section{MATERIALS AND METHODS}

\subsection{Transgenic Plants Production}

Genetic transformation of aspen was performed using in vitro plant material for genotype $\mathrm{Pt}$ provided by the Forest Institute of National Academy of Sciences (Padutov V.E., Gomel, Belarus). To carry out the Agrobacterium-mediated transformation we used supervirulent strain CBE21 [12] carrying the binary vector pBI-Xeg [13]. In the vectors' T-DNA there is a chimeric gene $s p$-Xeg of length $824 \mathrm{bp}$, under transcriptional control of the $35 \mathrm{~S}$ promoter and nopalinesynthase terminator. The gene $s p$ Xeg encodes a chimeric xyloglucanase XegA of Penicillium canescens with a signal peptide of cellulase from white poplar [13]. As selective gene in T-DNA of binary vector contains a gene nptII controlled by nopalinesynthase promoter. The internodes $4 \mathrm{~mm}-6 \mathrm{~mm}$ long from microplants in vitro were inoculated. Regeneration and selection of transformants was carried out on MS me- dium [14] modified by the content of nitrates [15] containing $2 \mathrm{mg} / \mathrm{l}$ zeatin, $0.5 \mathrm{mg} / 1$ indolyl-3-acetic acid, 30 $\mathrm{mg} / \mathrm{l} \mathrm{kanamycin}$ and $500 \mathrm{mg} / \mathrm{l}$ klaforan.

\subsection{Confirmation of Expression of the Recombinant Gene}

\subsubsection{PCR Analysis}

Transformants were analyzed by PCR method for the detection of sequences transferred from the T-DNA of the binary vector $\mathrm{pBI}-\mathrm{Xeg}$. For PCR were used primers for genes $\operatorname{VirB}$, nptII and $s p$-Xeg (Table 1). Possible contamination of total DNA by trace amounts of DNA of Agrobacterium was excluded by amplifying a fragment (670 bp) gene VirB using a pair of oligonucleotides VirB1 and VirB2. The presence of selective gene nptII was evaluated by PCR with oligonucleotides Nos and NptII. The size of the expected fragment was $741 \mathrm{bp}$. To amplify a fragment of the chimeric gene of xyloglucanases (762 bp) pair of oligonucleotides Xeg-up and Xeg-low (Table 1) was used.

\subsubsection{RT-PCR Analysis}

Transcription of the chimeric $s p$-Xeg gene was analyzed by RT-PCR. Plant total RNA was extracted from in vitro plant material by TRIzol ${ }^{\circledR}$ reagent (Invitrogen, USA) according to the attached commercial technology

(http://www.invitrogen.com). The reaction mixture was used for PCR with primers Xeg-up and Xeg-low. To control the contamination of the RNA by residues of genomic DNA PCR was performed with RNA preparations of each of the clones without treatment by reverse transcriptase.

\subsection{Analysis of Xyloglucanase Activity}

To receive the extracts of plant from greenhouse plants we used 4 leaves with 4 independent plants of each aspen genotype grown in a greenhouse for 1 month. The leaves of each genotype were ground to form a homogeneous suspension. The extracts were centrifuged. The supernatant was used to determine protein concentration by Bradford method [16] and the activity of xyloglucanase.

Table 1. The sequences of the oligonucleotides used.

\begin{tabular}{clc}
\hline Name of oligonucleotide & Nucleotide sequence (5',,$\ldots-3$ ') & Length, bp \\
\hline Vir-B1 & GGCTACATCGAAGATCGTATGAATG & 25 \\
Vir-B2 & GACTATAGCGATGGTTACGATGTTGAC & 27 \\
Nos & CGCGGGTTTCTGGAGTTTAATGAGCTAAG & 29 \\
NptII & GCATGCGCGCCTTGAGCCTGG & 21 \\
Xeg-up & GAAATGGCTAATGCCACTACATT & 23 \\
Xeg-low & GATTTAGGCAACATCGGCAG & 20 \\
\hline
\end{tabular}


To detect the activity of endo-1,4- $\beta$-glucanase plant extracts from transformed aspen we used the spectrophotometric method and the soluble substrate xyloglucan-tamarisk painted by Remazolbrilliant Blue. The analyses of the activity of the enzyme was performed according to the manufacturer of the substrate

(http://secure.megazyme.com). Measures are taken at a wavelength of $590 \mathrm{~nm}$. In the control sample instead of the plants extract $0.25 \mathrm{ml}$ of extraction buffer was added. The enzyme activity was calculated in relative units. The OD590 value of $1 \mathrm{ml}$ of the plant extract untransformed plants $(\mathrm{Pt})$ per $1 \mathrm{mg}$ of protein was accepted as one unit activity relative.

\subsection{Analysis of the Content of Pentosans}

The content of pentosans in wood was measured by the Tollens modified method [17], by converting them into furfurol during their distillation in the presence of $\mathrm{HCl}$. The stems of plants of not more than 4 months of age were peeled from the rind and $0.1 \mathrm{~g}$ of air-dried sawdust was prepared. The optical absorption of the distillate was measured by two-beam spectrophotometer at a wavelength of $277 \mathrm{~nm}$.

The pentosan content in the dry matter was calculated by the formula:

$$
A=D \times n \times K_{d r y} / m,
$$

$A$ - the percentage of pentosans in the air-dry sample; $D$-average of optical absorbance of the furfural solution obtained after its distillation; $n$-conversion coefficient of furfural to pentosans (for leaf wood-2434); $m$-mass of the sawdust sample, g; $K_{d r y}$-dryness coefficient. For better data understanding the percentage of pentosans were translated into absolute values- $\mathrm{mg} / \mathrm{g}$ dry weight.

\subsection{Analysis of Biometric Data}

To study the effect of the expression of the recombinant gene $s p$-Xeg on the phenotype of the transgenic aspen were prepared $40-50$ micropropagation of plants of each of the 25 clones and 2 control clones non-transgenic control $(\mathrm{Pt})$ and transgenic control (PtIGus5a). Measurements of the efficiency of rooting were conducted in vitro on the sixth day after transplanting the plants in a nutrient medium. We measured the length of each root of all plants. Rooting efficiency $(Y)$ is calculated as [18]:

$$
Y=N \times L / 10,
$$

$N$ - the average number of roots per plant; $L$-average length of roots of one plant $(\mathrm{mm})$.

The plants with closed root system age of 4 months were obtained in the greenhouse. To assess the phenotypic changes in aspen transgenic plants we took measurements across three parameters: plant height, number of nodes, weight of root system. Biometrics indicators were analyzed in 40 plants of each genotype.

All data were obtained in triplicate. The data were processed by methods of mathematical statistics [19]. Ranking data were carried out by Duncan's rank test for ANOVA-1 using the software Statistica 7.0.

\section{RESULTS}

\subsection{Obtaining the Transgenic Aspen Plants with the Recombinant Gene of $s p-X e g$}

As a result of agrobacterial transformation of aspen stem explants 25 transgenic lines chose on selective medium with kanamycin were received. Control plants of genotype Pt on medium with kanamycin didn't form roots and quickly died. In order to avoid the possibility of false-positive PCR for the presence of T-DNA sequences from the vector pBI-Xeg we analyzed the products of total plant DNA for the presence of Agrobacterium contamination. The analysis was performed by PCR using two primers on the gene virB. The expected size of the amplified fragment was $670 \mathrm{bp}$. All the analyzed samples did not show the presence of Agrobacterium contamination (data not shown). PCR analysis of genomic DNA of the derived kanamycin-resistant lines of aspen for the presence of selective nptII gene showed that all transformants contain the desired sequence, the size of the amplified fragment corresponded to the expected one $(741 \mathrm{bp})$. Subsequent analysis of the transformants for the presence of the sequence of recombinant gene $s p$-Xeg showed its presence in all the investigated lines. The size of the amplified fragment corresponded to the expected value (762 bp). The analysis of DNA samples for the presence of gene $s p-X e g$ in some transgenic lines is shown in Figure 1.

\subsection{Analysis of the Recombinant Gene sp-Xeg Transcription by RT-PCR in Transgenic Aspen}

To confirm the expression of the recombinant gene $s p-X e g$ in tissues of the greenhouse plants we performed RT-PCR analysis of total RNA samples for transgenic lines. All the 25 clones were investigated. As a control, we took non-transgenic aspen plants of genotype Pt and transgenic line PtIGus5a containing the reporter gene GUS. Amplification product of the expected size of 762 bp was found in all lines with integrated genome xyloglucanase. This confirms the presence of transcripts of the recombinant gene $s p$-Xeg (Figure 2).

\subsection{Analysis of Activity of Xyloglucanase in Transgenic aspen}

For the analysis of activity of xyloglucanase the plants extracts were obtained from 25 transformed and 2 


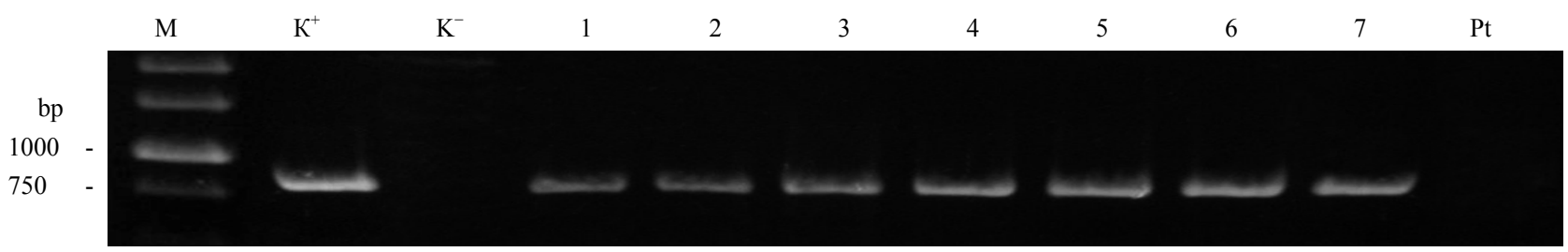

Figure 1. PCR analysis of transgenic aspen for the presence of the gene $s p-X e g . \mathrm{M}-$ molecular marker, $\mathrm{K}^{+}-\mathrm{plasmid} \mathrm{pBI}-\mathrm{Xeg} ; \mathrm{K}^{-}-$ Water, 1-7—transgenic lines (1-PtXVXeg1c; 2-PtXVXeg4a; 3-PtXVXeg4b; 4-PtXVXeg4c; 5-PtXVXeg5a; 6-PtXVXeg3a; $7-\mathrm{PtXVXeg5c)}$; $\mathrm{Pt}$ - non-transgenic plant. The size of the expected amplified fragment is $762 \mathrm{bp}$.

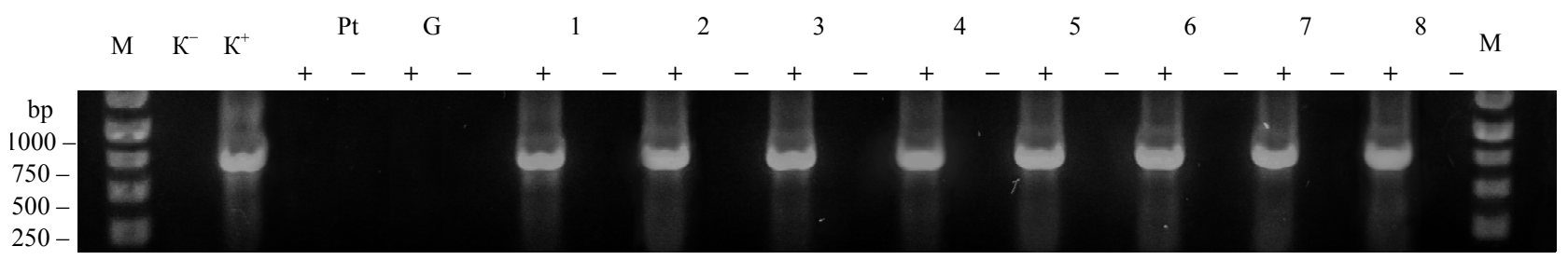

Figure 2. RT-PCR analysis of gene expression $s p-X e g$ in transgenic aspen (“+” RNA samples after treatment by reverse transcriptase, “_"-without reverse transcriptase treatment; $\mathrm{K}^{+}$— plasmid pBI-Xeg; $\mathrm{K}_{-}^{-}$-water; Pt—non-transgenic control; G-transgenic control PtIGUS5a; 1-8 - transgenic lines (1-PtXIVXeg1a; 2-PtXVXeg1a; 3-PtXVXeg1b; 4-PtXVXeg1c; 5-PtXVXeg2b; 6-PtXVXeg4c; 7-PtXVXeg5c; 8-PtXVIXeg1b); M-molecular marker.

control lines grown in the greenhouse. The xyloglucanase activity of the plants extracts grown in the greenhouse are shown on Figure 3. For four genotypes, we observed an increase the xyloglucanase activity compared with the control Pt:PtXVXeg1c by $92 \%$, PtXVXeg 4 c by $51 \%$, PtXIVXeg1a by $35 \%$, PtXIVXeg 1 b by $21 \%$. The enzyme activity of other studied genotypes was close to the control values.

\subsection{Analysis of the Content of Pentosans}

Pentosans are the sugars which at large form hemicellulose. The expected effect of overexpression of recombinant gene of xyloglucanase is the reduction of pentosans content in the cell walls of transgenic plants. To confirm this assumption, the analysis of the content of pentosans in wood of transgenic and control plants was carried out. In the control plants the content of pentosans was $148 \mathrm{mg} / \mathrm{g}$ dry weight, while in all the studied transgenic clones it varied from 100 to $140 \mathrm{mg} / \mathrm{g}$ dry weight (Figure 4). Maximal reduction (31\%) of the content of pentosans was observed for line PtXVXeg1c. The content of pentosans in this line was $102.1 \pm 1.5 \mathrm{mg} / \mathrm{g}$ dry weight.

\subsection{Analysis of the Biometric Characteristics}

For biometric analysis of plants in the greenhouse showed changes in the height of transgenic plants as compared to non-transgenic control genotype $(\mathrm{Pt})$. A significant increase in the stem height of $23 \%-26 \%$ was observed for lines PtXIVXeg1a, PtXVXeg1a, PtXVXeglb but also there was a line that was below the control one by about 14\%-PtXVXeg1c (Figure 5). Most of the

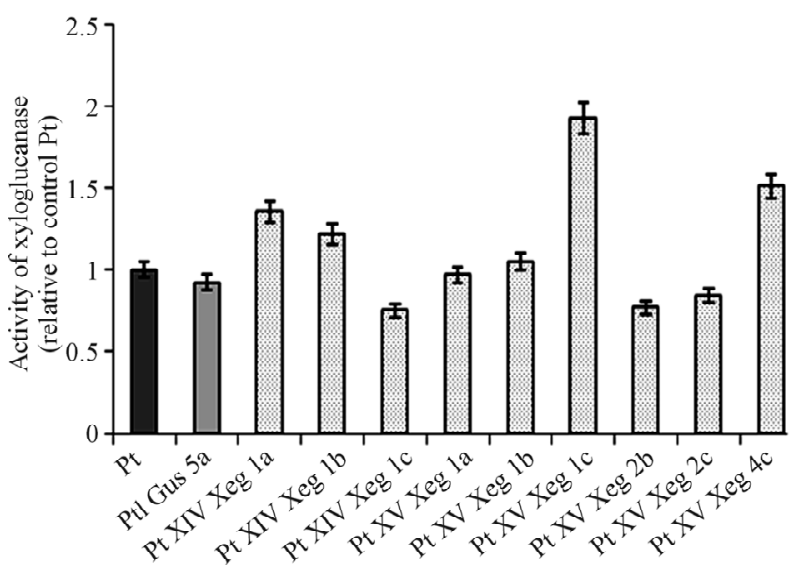

Figure 3. Analysis of xyloglucanase activity in transgenic and control plants (Pt, PtIGus5a).

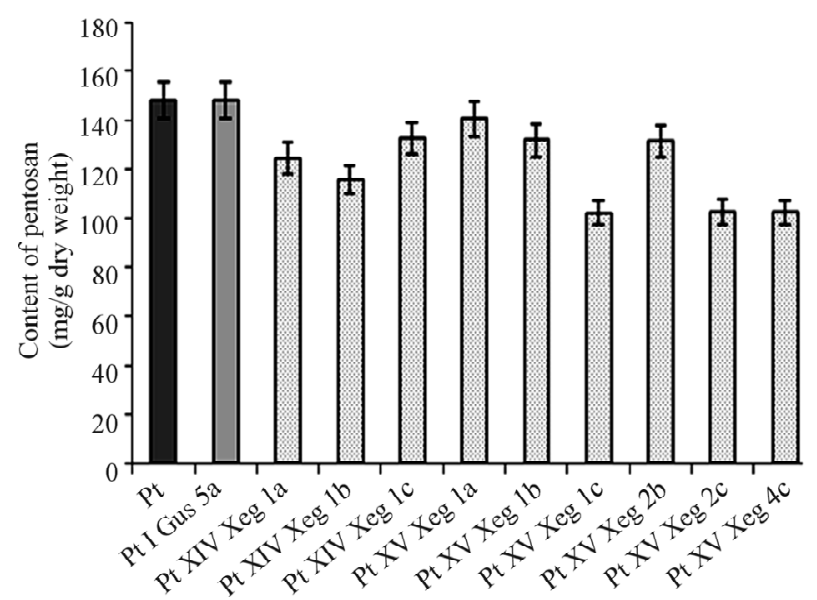

Figure 4. Analysis of the content of pentosan in the wood of transgenic and control plants (Pt, PtIGus5a). 


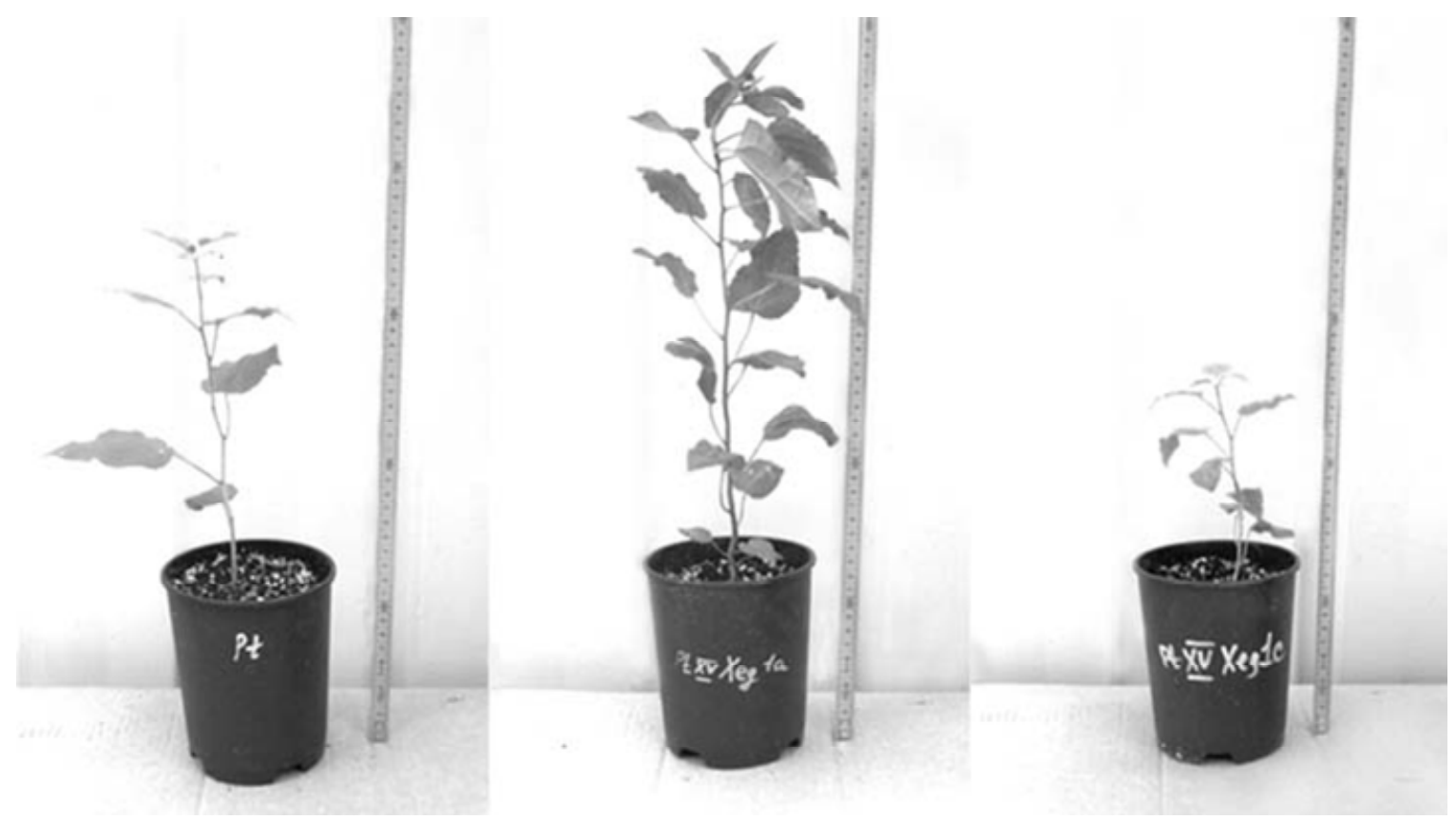

Figure 5. Plants of control line and transgenic aspen clones (from left to right: control-Pt, a clone with an increased rate of growth of $25 \%$-PtXVXeg1a, clone with a decreased growth rate of 14\%-PtXVXeg1c). The figure shows the average member of each group of plants.

lines were in height at the level of the control lines (Figure 6). Comparative analysis of leaf morphology of transgenic aspen clones showed an increase in the length of the petiole, and reduction in the length of the main vein [5]. In 20 of the 25 lines, the ratio of the length of the stem to the main vein was significantly higher than the control ones (Figure 7). In addition to changes in leaf morphology and an increase in the number of internodes in some transgenic plants was observed (Figure 6). The greatest difference from the control line $(\mathrm{Pt})$ - by about $18 \%$ - was seen for clone PtXIVXeg1a. The smallest number of internodes was in the plants of clone PtXVXeg1c-24\% below the control.

We analyzed the efficiency of in vitro rhizogenesis in the transgenic and control aspen lines. The efficiency of rooting of almost all transgenic lines was higher than in the control lines. In clone PtXVXeg1a it exceeded the reference value by 3.2 times. The data of root biomass in the greenhouse showed that biomass of clones roots increased by about $20 \%-25 \%$ compared with the control (Table 2). However, there were clone PtXVXeg1c whose biomass of the root system was lower than that of the control by $40 \%$. For clones PtXVXeg1a, PtXVXeg1b, PtXVXeg2c, PtXVXeg3b, PtXVXeg4b, PtXVXeg5b, Pt$X V X e g 5 c$ we noted conjugate increase in efficiency of in vitro rooting and of biomass of roots in the greenhouse compared to non-transgenic plants.

Based on the results of biometric analysis for the subsequent tests following PtXIVXeg1a, PtXVXeg1a, PtXVXeg1b lines with biometrics data exceeding the

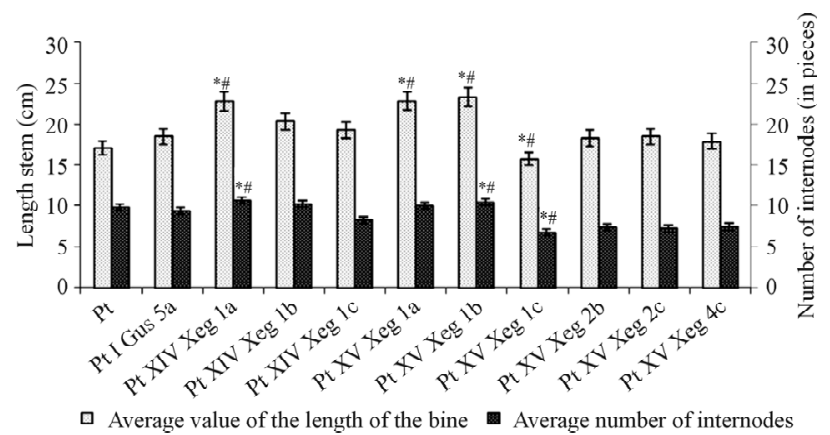

Figure 6. Comparative analysis of the height and number of internodes of transgenic and control plants ( ${ }^{*}$ Statistically significant difference from Pt, $\mathrm{p}<0.05$; ${ }^{\#}$ Statistically significant difference from PtIGus5a, $\mathrm{p}<0.05$ ).

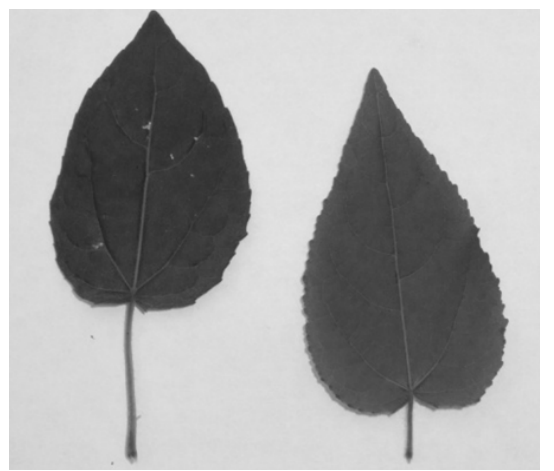

Figure 7. The leaves of the transgenic lines and controls. (from left to right: the transgenic line PtXIVXegla, the wild-type genotype Pt). 
controls values can be selected (Table 3).

\section{DISCUSSION}

Overexpression of carbohydrases in wood plants in a number of works is considered as one of the most promising ways of developing highly productive plants. In

Table 2. Rhizogenesis of transgenic aspen plants and the control group.

\begin{tabular}{lll}
\hline Clone & $\begin{array}{l}\text { Efficiency of } \\
\text { rooting in vitro }\end{array}$ & $\begin{array}{l}\text { Mass of rooting } \\
\text { system. g wet weight }\end{array}$ \\
\hline Pt & $1.74 \pm 0.03^{\mathrm{a}}$ & $3.89 \pm 0.09^{\mathrm{a}}$ \\
Pt I Gus 5a & $1.45 \pm 0.06^{\mathrm{a}}$ & $2.99 \pm 0.11^{\mathrm{a}}$ \\
The average values of & $1.6 \pm 0.05^{\mathrm{a}}$ & $3.44 \pm 0.10^{\mathrm{a}}$ \\
the control & $2.38 \pm 0.06^{\mathrm{b}}$ & $3.00 \pm 0.09^{\mathrm{a}}$ \\
Pt XIV Xeg 1a & $3.03 \pm 0.07^{\mathrm{b}}$ & $3.32 \pm 0.10^{\mathrm{a}}$ \\
Pt XIV Xeg 1b & $3.09 \pm 0.08^{\mathrm{b}}$ & $3.50 \pm 0.11^{\mathrm{a}}$ \\
Pt XIV Xeg 1c & $5.16 \pm 0.1^{\mathrm{c}}$ & $4.40 \pm 0.14^{\mathrm{a}}$ \\
Pt XV Xeg 1a & $2.57 \pm 0.04^{\mathrm{b}}$ & $6.00 \pm 0.18^{\mathrm{b}}$ \\
Pt XV Xeg 1b & $1.79 \pm 0.08^{\mathrm{a}}$ & $1.44 \pm 0.10^{\mathrm{c}}$ \\
Pt XV Xeg 1c & $1.38 \pm 0.04^{\mathrm{a}}$ & $2.80 \pm 0.08^{\mathrm{a}}$ \\
Pt XV Xeg 2a & $4.47 \pm 0.05^{\mathrm{c}}$ & $4.03 \pm 0.12^{\mathrm{a}}$ \\
Pt XV Xeg 2c & $3.83 \pm 0.03^{\mathrm{b}}$ & $3.60 \pm 0.11^{\mathrm{a}}$ \\
Pt XV Xeg 3a & $2.66 \pm 0.06^{\mathrm{b}}$ & $3.93 \pm 0.12^{\mathrm{a}}$ \\
Pt XV Xeg 3b & $1.86 \pm 0.06^{\mathrm{a}}$ & $7.26 \pm 0.22^{\mathrm{b}}$ \\
Pt XV Xeg 4b & $1.14 \pm 0.05^{\mathrm{a}}$ & $3.90 \pm 0.12^{\mathrm{a}}$ \\
Pt XV Xeg 4c & $2.87 \pm 0.04^{\mathrm{b}}$ & $6.36 \pm 0.19^{\mathrm{b}}$ \\
Pt XV Xeg 5b & $2.83 \pm 0.08^{\mathrm{b}}$ & $6.14 \pm 0.18^{\mathrm{b}}$ \\
Pt XV Xeg 5c & & $0.055019 n$ \\
\hline
\end{tabular}

Note: After the ranking Duncan test ANOVA-1, $\mathrm{P} \leq 0.05$ different groups of values were indentified.

Table 3. A general characteristics of promising clones.

\begin{tabular}{|c|c|c|c|c|}
\hline Characteristic & $\begin{array}{l}\text { Control, } \\
\mathrm{Pt}\end{array}$ & PtXIVXeg1a & PtXVXegla & PtXVXeglb \\
\hline $\begin{array}{c}\text { Height, cm } \\
\text { (for } 4 \text { month age) }\end{array}$ & 17.12 & 22.76 & 22.8 & 23.33 \\
\hline $\begin{array}{l}\text { Efficiency of } \\
\text { rooting in vitro }\end{array}$ & 2.14 & 2.38 & 5.16 & 2.57 \\
\hline $\begin{array}{l}\text { Analysis of the } \\
\text { activity of } \\
\text { xyloglucanase, } \\
\text { in relation to the } \\
\text { Pt control }\end{array}$ & 1 & 1.35 & 1.02 & 1.06 \\
\hline $\begin{array}{c}\text { Content of } \\
\text { pentosans, mg/g of } \\
\text { dry weight }\end{array}$ & 148.3 & 124.5 & 140.4 & 131.8 \\
\hline
\end{tabular}

previously published studies the authors discussed the modification of Populus tremula by gene cell endoglucanase from Arabidopsis thaliana [4], and Populus alba by AaXeg2 xyloglucanase from Aspergillus aculeatus [3]. In both cases it was reported about the increase of the growth rate of plants, internode length and diameter of the stem. Along with changes in morphological traits a change in the chemical composition of plants wood due to overexpression the genes of xyloglucanases was revealed. In the Populus alba the reduction of hemicellulose $(24 \%)$ and increase of the xyloglucanase activity in stems was found [3].

The analysis of the content of pentosans in the wood of our transgenic clones is consistent with the scientific data [3]. All analyzed lines showed reduction in the content of pentosans. Analysis of protein extracts of greenhouse plants showed that xyloglucanase activity of PtXVXeg1c line was 1.9 time over the control value; while the content of pentosans in wood of this clone was the lower- $102 \mathrm{mg} / \mathrm{g}$ which is $31 \%$ lower than the control (148 mg/g of dry weight). Such dependence was witnessed for other clones, e.g. for clone PtXIVXeg1a the xyloglucanase activity was 1.5 times higher, and the content of pentosans was $124 \mathrm{mg} / \mathrm{g}$ of dry weight which is $16 \%$ lower than the control. This may indicate the connection between the content of pentosans and overexpression of xyloglucanase.

We obtained height values for transgenic clones PtXIVXeg1a, PtXVXeg1a, PtXVXeg1b that are comparable with the data from Shani et al., (2004) and Park et al., (2004) [3,4]. Of great interest is the ratio of the activity of xyloglucanase in greenhouse plants with biometric parameters of height of these plants because xyloglucanases were involved in the growth of plants mechanisms [6]. We can note that the clones with high activity of the enzyme (PtXVXeg1c, PtXVXeg4c) aren't above height or lower than the control plants. Indeed, in case of the constitutive overexpression of foreign genes it is sometimes marked that there are abnormalities in growth and development, for example dwarfism [20]. Genotypes PtXIVXeg1a and PtXVXeg1b, in which the activity of the recombinant enzyme is slightly higher than the control value, significantly exceed the height of non-transgenic plants. Thus, a small increase of xyloglucanase activity is likely to affect the increase in the plant growth rate. We noted a significant increase in height interrelated with the change in the number of internodes. This feature which is characteristic to the majority of our transgenic clones has not been described by other authors.

One of the unexpected effects of influence of the gene $s p$-Xeg became the modification of the formation of roots. The rise of in vitro rhizogenesis for some genotypes corresponded to the increase in root biomass in the green- 
house. For plants of the genus Populus positive impact of the overexpression of xyloglucanase genes on the formation of the root system was not previously observed [11]. Supposedly, the observed effect is connected with the influence of xyloglucanase on the properties of the cell walls and the ability of root cell for elongation, as well as on signal transduction through the auxins receptors [21]. Obviously the efficiency of rhizogenesis and biomass of root system may be accompanied by an increase in growth above-ground organs. The increase in the growth rate in turn should be accompanied by changes in the nutrients coming into the plant [22]. Thus, in the clones with high growth rate PtXIVXeg1a, PtXVXeg1a, PtXVXeg1b we observed the increase of the efficiency of rooting while at the same time for clone PtXVXeg1c with the reduction of growth a decrease in rhizogenesis was witnessed.

Morphological changes also affect the length of the stem and the length of the main vein. Analysis of the ratio of the length of the petiole to the main vein revealed a significant increase in this index in 20 of the 25 lines. Similar results of increase in the length of the stem [7] and a decrease in the length of the main vein [8] have been shown in conditions of the increase in splitting xyloglucan in Arabidopsis thaliana plants.

\section{CONCLUSIONS}

In conclusion, it should be noted that based on the results of the study of the properties of transgenic aspen plants with the gene $s p-X e g$ in greenhouse we may identify three highly productive lines PtXIVXeg1a, PtXVXeg1a and PtXVXeg1b (Table 3). Isolated clones have a number of advantages over the wild-type and the other clones: increased growth rate, increased efficiency of rooting and reduced content of hemicellulose. Further research is needed to study the biology of these clones in the field conditions.

This work was financially supported by the Ministry of Education and Science of the Russian Federation under the State contract No. 11.519.11.6043 from 20.06.2012, and No. 16.M04.12.0009 from 14.04.2011.

\section{REFERENCES}

[1] Bauman, M.J., Eklo, G., Michel, M., Kallas, T.T., Teeri, M., Czjzek, H. and Brumer H. (2007) Structural evidence for the evolution of xyloglucanase activity from xyloglucan endo-transglycosylases. Biological implications for cell wall metabolism. The Plant Cell, 19, 1947-1963. doi:10.1105/tpc.107.051391

[2] Takeda, T., Furuta, Y., Awano, T., Mizuno, K., Mitsuishi, Y. and Hayashi, T. (2002) Suppression and acceleration of cell elongation by integration of xyloglucans in pea stem segments. Proceedings of the National Academy of Sciences of the United States of America, 99, 9055-9060. doi:10.1073/pnas.132080299
[3] Park, Y.W., Baba, K., Furutab, Y., Iidab, I., Sameshimac, K., Araid, M. and Hayashi T. (2004) Enhancement of growth and cellulose accumulation by overexpression of xyloglucanase in poplar. FEBS Letters, 564, 183-187. doi:10.1016/S0014-5793(04)00346-1

[4] Shani, Z., Dekel, M., Tsabary, G., Goren, R. and Shoseyov, O. (2004) Growth enhancement of transgenic poplar plants by overexpression of Arabidopsis thaliana endo-1,4- $\beta$-glucanase (cel1). Molecular Breeding, 14, 321-330. doi:10.1023/B:MOLB.0000049213.15952.8a

[5] Shestibratov, K.A. Podrezov, A.S., Salmova, M.A., Kovalitskaya, Yu A., Vidyagina, E.O., Loginov, D.S., Koroleva, O.V. and Miroshnikov A.I. (2012) Phenotypic expression of gene expression xyloglucanase from Penicillium canescens in transgenic plants aspen. Russian Journal Plant Physiology, 59, 1-9.

[6] Hartati, N.S, Rahayuningsih, L., Kaida, R., Sudarmonowati, E. and Hayashi T. (2009) Overexpression xyloglucanase gene in sengon (Paraserianthes falcataria) for growth acceleration. Journal of Biotechnology Research in Tropical Region, 2, 1-4.

[7] Sasidharan, R., Chinnappa, C.C., Staal, M., Elzenga, J., Yokoyama, R., Nishitani, K., Voesenek, L. and Pierik R. (2010) Light quality-mediated petiole elongation in arabidopsis during shade avoidance involves cell wall modification by xyloglucan endotransglucosylase/eydrolases. Plant Physiology, 154, 978-990. doi:10.1104/pp.110.162057

[8] Sampedro, J., Pardo, B., Gianzo, C., Guitión, E., Revilla, G. and Zarra, I. (2010) Lack of $\beta$-xylosidase activity in Arabidopsis alters xyloglucan composition and results in growth defects. Plant Physiology, 154, 1105-1115. doi:10.1104/pp.110.163212

[9] Reiter, W.-D., Chapple, C. and Somerville, C.R. (1993) Altered growth and cell walls in a fucose-deficient mutant of arabidopsis. Science, 261, 1032-1035. doi:10.1126/science.261.5124.1032

[10] Mellerowicz, E., Immerzeel, P. and Hayashi T. (2008) Xyloglucan: The molecular muscle of trees. Annals of $\mathrm{Bo}$ tany, 102, 659-665. doi:10.1093/aob/mcn170

[11] Taniguchi, T., Konagaya, K., Kurita, M., Takata, N., Ishii, K., Kondo, T., Funahashi, F., Ohta, S., Kaku, T., Baba, K., Kaida, R. and Hayash, T. (2012) Growth and root sucker ability of field-grown transgenic poplars overexpressing xyloglucanase. Journal Wood Sciences, 7, 1-7.

[12] Revenkova, E.V., Baghyan, I.L., Pozmogova, G.E. and Edges, A.S. (1994) Development of a new vector system based on the strain Agrobacterium tumefaciens A281. Molecular Genetic, Microbiology and Virology, 5, 36.

[13] Vidyagina, E.O., Kovalitskaya, Yu.A., Salmova, M.A., Loginov, D.S., Koroleva, O.V. and Shestibratov K.A. (2012) Effect of xyloglucanase gene XegA from Penicillium canescens expression on phenotype of transgenic aspen. 7th SPPS PhD Student Conference.

[14] Murashige, T. and Skoog F. (1962) A revised medium for rapid growth and bioassays with tobacco cultures. Plant Physiology, 15, 473-497. doi:10.1111/j.1399-3054.1962.tb08052.x

[15] Shestibratov, K.A., Bulatova, I.V., Shadrina, T.E. and 
Miroshnikov A.I. (2008) Genetic transformation of triploid forms of aspen and birch plus forms. Self-organizing distributed sensor networks. Proceedings of the VIII International Conference of Young Scientists "Forests of Eurasia-The North Caucasus", Sochi, 151.

[16] Bradford, M.M. (1976) A rapid and sensitive method for the quantitation of microgram quantities of protein utilizing the principle of protein-dye binding. Analytical Biochemistry, 72, 248-254. doi:10.1016/0003-2697(76)90527-3

[17] Obolenskaya, A.V., Yelnitskiaya, Z.P. and Leonovich, A.A. (1991) Laboratory work on the chemistry of wood. Ecology, Moscow, 320.

[18] Jiang, H.J., Pan, J.S. and Men, X.F. (1993) The study of meristem-tip culture of peach (Prunus persica L.). Journal of China Agricultural University, 19, 49-52.

[19] Zaitsev, G.N. (1984) Mathematical Statistics in experi- mental botany. Science, Moscow, 236-424.

[20] Liu, Y.B., Lu, S.M., Zhang, J.F., Liu, S. and Lu, Y.T. (2007) A xyloglucan endotransglucosylase/hydrolase involves in growth of primary root and alters the deposition of cellulose in Arabidopsis. Planta, 6, 1547-1560. doi:10.1007/s00425-007-0591-2

[21] Catala, C., Rose, J., York, W., Albersheim, P., Darvill, A. and Bennett A. (2001) Characterization of a tomato xyloglucan endotransglycosylase gene that is down-regulated by auxin in etiolated hypocotyls. Plant Physiology, 127, 1180-1192.

[22] Cosgrove, D.J. (1993) Water uptake by growing cells: An assessment of the controlling roles of wall relaxation, solute uptake and hydraulic conductance. International Journal of Plant Sciences, 154, 10-21. doi:10.1086/297087 